\title{
Habitat and food selection by herbivorous amphipods associated with macroalgal beds on the southeast coast of Brazil
}

\author{
Mauro Rezende Tavares, Henrique Grande and Giuliano Buzá Jacobucci*
}

(MRT, GBJ) Laboratório de Ecologia de Ecossistemas Aquáticos, Instituto de Biologia, Universidade Federal de Uberlândia (UFU). Rua Ceará s/nº, Campus Umuarama, CEP. 38400-902, Uberlândia - MG, Brazil. E-mail: jacobucci@inbio.ufu.br

(HG) Laboratório de Ecologia e Pesca (LAEPP, LABMAR), Universidade Federal de Alagoas, Rua Aristeu de Andrade 45, Bairro Farol, CEP. 57021-090, Maceió - AL, Brazil.

*Corresponding author

\begin{abstract}
The factors that influence the selection of marine macrophytes by meso-herbivores are complex, and may include the nutritional quality of algae, the value of the habitat as a shelter, and the availability of algae in the environment. Here we investigated the existence of differential use of Sargassum filipendula C. Agardh, 1824 (Phaeophyta) and Galaxaura stupocaulon Kjellman, 1900 (Rhodophyta) as habitats and feeding resources by species of Hyalidae and Ampithoidae, in laboratory manipulation experiments and in an algal bed on the northern coast of the state of São Paulo, Brazil. In the field, 19 fronds were collected from each alga and the associated amphipods were identified and counted. To evaluate food preference and habitat selection by amphipods, we conducted laboratory experiments using containers containing fragments of algae and individuals of Cymadusa filosa Savigny, 1816 or Hyale nigra (Haswell, 1879). In natural conditions, the density of $C$. filosa was significantly higher on $G$. stupocaulon, while in the feeding and habitat preference experiment we found a higher density on $S$. filipendula. The densities of $H$. nigra did not differ between the algae in both experiments, probably as a result of the variety of food items in its diet, and its high mobility and wide distribution on different substrates. The different results for $C$. filosa suggest that the pattern of feeding and habitat selection can be affected by external characteristics of the algae; probably, refuge from predation is an important selective force acting on the use of algae by these animals.
\end{abstract}

Key words: Amphipods, food choice, habitat choice, predation refuge

\section{INTRODUCTION}

The term phytal has been used to designate a marine biotype where there are interrelationships between marine animals and macrophytes (Masunari and Forneris, 1981). These macroalgae can occur in dense banks, forming patches that provide substrate for diverse faunistic groups, mainly the amphipods, the most important group of peracarid crustaceans in terms of richness and abundance in benthic communities (Thomas, 1993; Jacobucci and Leite, 2002).

The effects of amphipods and other meso-herbivores on the banks of aquatic macrophytes are fundamental in the dynamics of these ecosystems, promoting the cycling of nutrients (Klumpp et al., 1992), influencing the transfer of energy between trophic levels 
(Brawley, 1992), and affecting the productivity of benthic communities (Van Montfrans et al., 1982).

The factors that influence the selection of algae by meso-herbivores are complex and may include, for example, the nutritional quality of algae, the value of the habitat as a shelter against environmental stress (Jormalainen et al., 2001), and the availability of algae (Nicotri, 1980; Lubchenco and Gaines, 1981; Arrontes, 1990).

It is expected that food will be selected according to its palatability, energy content, digestibility and efficiency in algae absorption (Jernakoff et al., 1996). However, the feeding preference of meso-herbivores may not necessarily be related to the algal nutritional qualities (Nicotri, 1980). The value of the algae as a habitat can affect the feeding patterns on the potential algal hosts (Hay, 1992; Arrontes, 1999); in such a situation, protection from predators may override feeding preferences (Hay et al., 1987; Hay et al., 1989). According to Duffy and Hay (1991) and Duffy et al. (2001), predation could be the most important factor in regulating the densities of phytal invertebrates.

The effects of meso-herbivores can be equally as important as physical and chemical factors in structuring macrophyte communities (Duffy and Hay, 2000). Nevertheless, little is known about the feeding and habitat preferences of amphipods from the families Ampithoidae and Hyalidae. Of the five species of Hyalidae and three of Ampithoidae found on the coast of São Paulo (Leite et al., 2000), the diets of only Apohyale media (Dana, 1853) and Parhyale hawaiensis (Dana, 1853) have been investigated in Brazil (Tararam et al., 1985; Perreira and Yoneshigue-Valentin, 1999).

This study sought to determine the existence of differential utilization of Sargassum filipendula C. Agardh, 1824 (Phaeophyta) and Galaxaura stupocaulon Kjellman, 1900 (Rhodophyta) as habitats and feeding resources by species of Hyalidae and Ampithoidae, in laboratory manipulation experiments and in a bank of macroalgae on the northern coast of the state of São Paulo, Brazil.
Specifically, we posed the following questions: Do the species of Hyalidae and Ampithoidae occur in different densities on the macroalgae? Do the most abundant species of Hyalidae and Ampithoidae prefer different habitats (macroalgal species)? Do the most abundant species of Hyalidae and Ampithoidae show feeding preferences for different macroalgal species?

\section{Material And Methods Study area}

The samples were collected on the northern coast of the state of São Paulo, Brazil (Fig. 1 ), in the infralittoral zone of Fortaleza Beach $\left(23^{\circ} 31^{\prime} \mathrm{S} / 45^{\circ} 09^{\prime} \mathrm{W}\right)$ in the Municipality of Ubatuba. Much of this part of the coast is rocky, affording a wide variety of substrates (Perreira and Jacobucci, 2008). The rocky shore where the samples were collected has an average depth of $2.5 \mathrm{~m}$ and is moderately protected from wave action, according to the criteria used by Széchy and Paula (2000). The brown alga Sargassum filipendula is dominant in the area, and Galaxaura stupocaulon (Rhodophyta), Padina gymnospora (Kützing) Sonder (Phaeophyta), and Caulerpa racemosa (Forsskal) J.Agardh, 1872 (Chlorophyta) also occur at the sampling site.

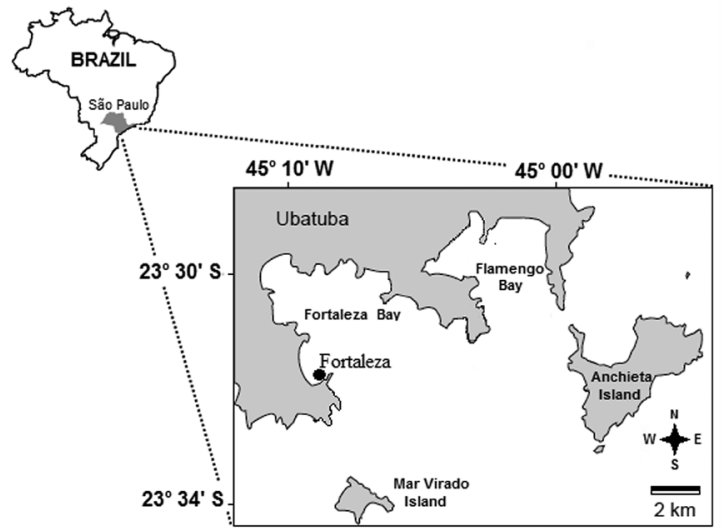

Figure 1. Location of the study area, Fortaleza Beach (2332'S, 4506'W), Ubatuba, state of São Paulo, Brazil.

\section{Collection and treatment of samples}

We collected 19 fronds from each of the dominant species of algae ( $S$. filipendula and G. stupocaulon) in an area in the infralittoral zone of Fortaleza Beach where beds of $S$. 
filipendula are approximately $50 \mathrm{~m}$ distant from beds of $G$. stupocaulon. Using snorkeling, we enclosed the fronds in a cloth bag with a $0.2 \mathrm{~mm}$ mesh size and removed them from the holdfast with the aid of a spatula (Jacobucci et al., 2009).

In the laboratory, each frond was placed in a separate dish with a solution of $4 \%$ formaldehyde in sea water, and was washed four times to remove the macrofauna. The wash water was filtered through a $0.2 \mathrm{~mm}$ cloth bag to retain the organisms, which were then placed in a $70 \%$ ethanol solution. This process removes around $99 \%$ of the vagile epifauna from the fronds (Taylor and Cole, 1994). The amphipods of the families Ampithoidae and Hyalidae were counted and identified to species level with a stereoscopic microscope. The species were identified according to Conlan (1982) and Serejo (2004). Voucher specimens were preserved in $70 \%$ ethanol and deposited in the reference collection of the Laboratory of Aquatic Ecosystems Ecology in the Institute of Biology at the Federal University of Uberlândia, Brazil. The dry mass of the Sargassum fronds was obtained after drying at $60^{\circ} \mathrm{C}$ for $48 \mathrm{~h}$ (Jacobucci et al., 2009).

\section{Food preference and habitat selection experiments}

To evaluate food preference and habitat selection, the two most abundant amphipod species recorded in the sampling location, Hyale nigra (Haswell, 1879) and Cymadusa filosa Savigny, 1816, were used. In the feedingpreference experiment, we used 10 individuals of $C$. filosa and 10 of $H$. nigra, taken from 10 fronds of $S$. filipendula and 10 of $G$. stupocaulon. The amphipods were removed by dipping and rinsing the fronds for a few minutes in seawater. From these fronds, small fragments of algae were removed, standardized by their volume as measured in a pipette, and subsequently dried on paper towels for $30 \mathrm{~s}$ and weighed on an analytical balance.

The fragments were placed in pairs, one in each end of a glass container, with a volume of $155 \mathrm{ml}$. Then, one amphipod was introduced. Ten replicates were used for each species of amphipod. Ten controls (without amphipods) for each amphipod species were kept in the same conditions for the same period as for the replicates, with the objective of evaluating possible losses of algal biomass, independently of consumption by the amphipods (Szlávecz, 1985). After $24 \mathrm{~h}$, the fragments of macroalgae were removed from the system, dried on paper towels for 30 $s$, and weighed again on an analytical balance. The estimated consumption of each alga by the amphipods was calculated by subtracting the mean value for algal mass remaining in the replicates with the amphipods, from the mass in the control replicates without amphipods.

In the habitat-selection experiment, ten plastic containers $30 \mathrm{~cm}$ in length, $20 \mathrm{~cm}$ in width and $10 \mathrm{~cm}$ tall and provided with aerators were used. Fragments of macroalga were added, with a different species in each end of the container. Ten amphipods of similar sizes were placed in each container with the two fragments of macroalgae. Ten replicates were used for each species of amphipod. The amphipods were allowed to acclimate for 24 $\mathrm{h}$, in a $12 \mathrm{~h}$ light/dark cycle in an ambient temperature of $25^{\circ} \mathrm{C}$. In order to check to which fragments of algae the individuals moved, and thus observe which substrate the species prefers, each fragment of algae was washed separately and then the individuals present were identified and counted. Because the experiments were conducted in a controlled environment and over a short period, no mortality of the amphipods was observed.

\section{Data analyses}

The taxonomic groups were expressed as number of individuals per gram of dry mass of Sargassum or Galaxaura, to standardize the abundance data. To compare the natural densities of individuals per algal species, the Mann-Whitney test for independent samples was used.

The feeding preference of each species was evaluated by comparing the amount of algae consumed, through the $\mathrm{T}$ test for paired samples. To test the selection of substrate, a chi-square test $\left(\chi^{2}\right)$ was used to compare the proportions found in the experiment on substrate selection. 


\section{RESULTS}

\section{Characterization of phytal macrofauna}

A total of 1,240 individual amphipods were collected, 476 on Sargassum filipendula and 764 on Galaxaura stupocaulon. The most abundant species on $S$. filipendula was Hyale nigra, which comprised $52 \%$ of the total of amphipods encountered. On G. stupocaulon the most abundant species was Cymadusa filosa, which comprised $66 \%$ of the total organisms. The less-numerous species on $S$. filipendula were Ampithoe ramondi Audouin, 1826, Sunampithoe pelagica (Milne-Edwards, 1830), and C. filosa. On G. stupocaulon, $H$. nigra, S. pelagica, and $A$. ramondi were less abundant (Table 1).

Table 1. Amphipods recorded on fronds of the macroalgae Sargassum filipendula and Galaxaura stupocaulon, with their total and relative (\%) abundances. Ind = number of individuals.

\begin{tabular}{lccccc}
\hline Family/Species & \multicolumn{2}{c}{$\begin{array}{c}\text { Sargassum } \\
\text { filipendula }\end{array}$} & & \multicolumn{2}{c}{$\begin{array}{c}\text { Galaxaura } \\
\text { stupocaulon }\end{array}$} \\
\cline { 2 - 3 } & Total (Ind) & $\%$ & & Total (Ind) & $\%$ \\
\hline Hyalidae & & & & & \\
$\quad$ Hyale nigra & 247 & 52 & & 41 & 6 \\
Ampithoidae & & & & \\
$\quad$ Cymadusa filosa & 84 & 18 & & 506 & 66 \\
$\quad$ Ampithoe ramondi & 69 & 14 & & 170 & 22 \\
$\quad$ Sunampithoe pelagica & 76 & 16 & & 47 & 6 \\
Total & 476 & 100 & 764 & 100 \\
\hline
\end{tabular}

Comparison of natural densities

The Mann-Whitney test indicated significantly higher densities of $C$. filosa $(\mathrm{U}=46 ; \mathrm{p}=0.0001)$ and $A$. ramondi $(\mathrm{U}=$ $86 ; \mathrm{p}=0.0061)$ on Galaxaura in relation to Sargassum. Hyale nigra $(\mathrm{U}=139 ; \mathrm{p}=0.2257)$ and $S$. pelagica $(\mathrm{U}=160.5 ; \mathrm{p}=0.5593)$ did not show significant differences in their densities between the two algae (Fig. 2).

\section{Habitat selection and feeding preference}

In the habitat-selection experiment, when fragments of both algae were offered, C. filosa showed a preference for fragments of S. filipendula as a substrate $\left(\chi^{2}=16\right.$; g.L $=1 ; \mathrm{p}<0.05)$, with $70 \%$ of the individuals associated with S. filipendula and 30\% with $G$. stupocaulon (Fig. 3). Likewise, C. filosa showed a significantly greater feeding preference for $S$. filipendula over $G$. stupocaulon $(\mathrm{t}=1.93$; g. $\mathrm{L}=$ 9; $<<0.05$ ) (Fig. 4).
Hyale nigra showed no significant preference for either of the algae offered as a substrate $\left(\chi^{2}=0.64 ; \mathrm{g} . \mathrm{L}=1 ; \mathrm{p}>0.05\right)$ : at the end of the experiment $46 \%$ of the individuals were associated with $S$. filipendula and the remainder with $G$. stupocaulon (Fig. 3). In relation to feeding preference, no significant differences were noted in the consumption of S. filipendula and G. stupocaulon ( $\mathrm{t}=-1.19$; g.L $=9 ; \mathrm{p}>0.05)($ Fig. 4).

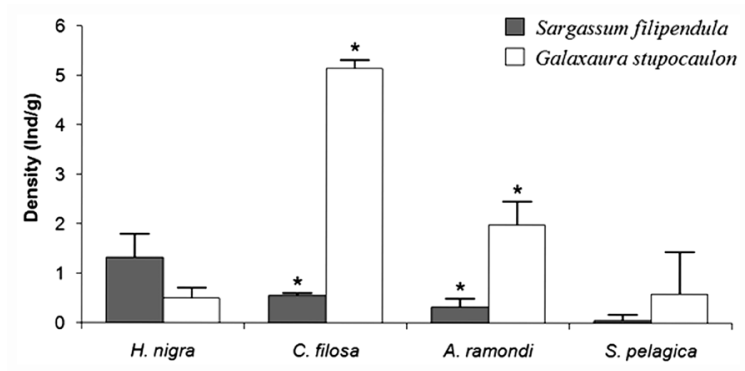

Figure 2. Mean density (+SE) of amphipod species on the macroalgae Sargassum filipendula and Galaxaura stupocaulon. *Indicates significant differences among macroalgae.

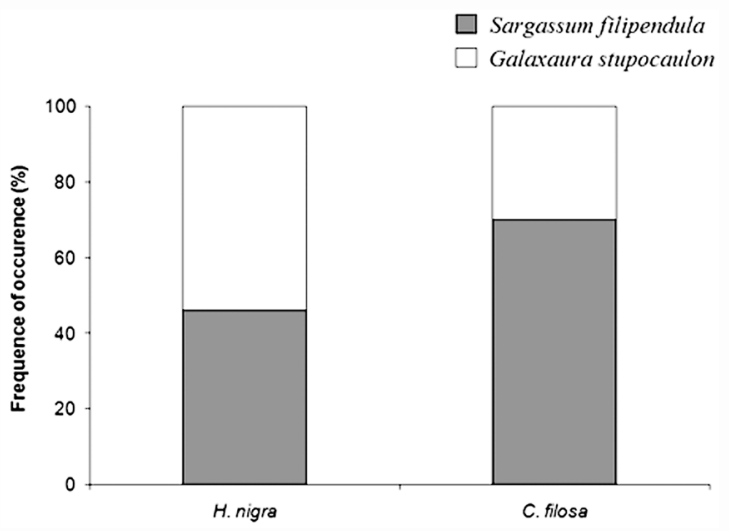

Figure 3. Frequency of occurrence of Hyale nigra and Cymadusa filosa on fragments of the macroalgae $S$. filipendula and $G$. stupocaulon at the end of the preference experiment.

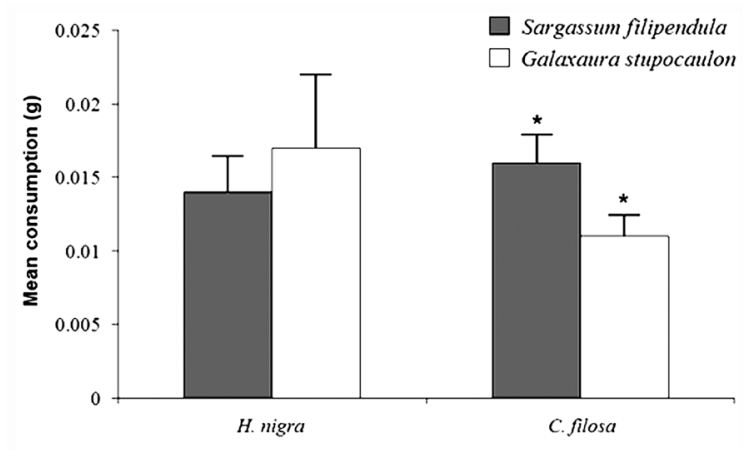

Figure 4. Mean consumption (+ SE) of Sargassum filipendula and Galaxaura stupocaulon by the amphipods Cymadusa filosa and Hyale nigra. *Indicates significant differences among macroalgae. 


\section{Discussion}

Our results indicate that the ampithoid Cymadusa filosa showed a preference for certain types of macrophytes as food or habitat. However, habitat selection by C. filosa differed in the laboratory and in the field. The hyalid Hyale nigra showed no preference for either alga as a feeding resource or substrate.

In the field, C. filosa and Ampithoe ramondi showed significantly higher densities on Galaxaura stupocaulon. However, the laboratory experiments indicated a preference for food and habitat on Sargassum filipendula. Many experiments have established that the nutritional quality and chemical content of algae, in addition to the morphological characteristics and size of the amphipods, can determine feeding preferences (Nicotri, 1980; Brawley, 1992). However, the divergence between the results from the field observations and from the laboratory experiments suggests that for C. filosa, the feeding pattern and habitat selection could be affected by external characteristics of the algae. This implies that the feeding preference and the capacity to use the habitat for growth could have evolved in conjunction.

Therefore, the dominance of C. filosa on G. stupocaulon in natural conditions could be related to the use of algae as a refuge against predation. According to Hay et al. (1990), the value of algae as a refuge or shelter against predation can be especially important for the evolution of the use of host algae by herbivorous amphipods. The presence of predators frequently restricts the aquatic prey to the refuge that offers the most protection, even though it may have a low foraging value (Mattingly and Butler, 1994).

The regulation of amphipod populations through predation is an important factor for selection in a phytal community (Nelson, 1979), responsible for molding the characteristics of prey such as morphology, physiology, behavior and life cycle (Mattingly and Butler, 1994). According to Wakabara $e t$ al. (1996), the density of amphipod predators is higher in the colder months, as in the period of sample collection, which would increase the predation pressure on the amphipods. This characteristic, together with the low mobility and relatively larger size of $C$. filosa and $A$. ramondi in relation to other species of amphipods, makes them more susceptible to visual predators such as fish (Mattila, 1992; Isaksson et al., 1994).

The more-compact structure of $G$. stupocaulon retains large amounts of sediments and nutrients (Iribarne, 1996), which may better protect the associated animals by hindering visual detection by predators (Stoner, 1980), favoring suspension-feeding and detritivorous species and providing raw materials for tubiculous species such as ampithoids to construct their homes (Norton and Benson, 1983).

The preference for G. stupocaulon may also be associated with the availability of the algae in the natural environment. According to Hughes (1980), the availability and abundance of a food supply affects the amount of time and energy necessary for the herbivore to locate its food. The banks of seaweed of Fortaleza Beach are not distributed homogeneously, with patches of other species of algae (unpublished data). The bank of G. stupocaulon sampled was relatively isolated by a sandbar, around $50 \mathrm{~m}$ from the bank of S. filipendula. The low mobility of the tubiculous species $C$. filosa and A. ramondi could have caused an aggregation effect due to the isolation of the bank of $G$. stupocaulon, resulting in a higher density of these species at that location.

In the experiment, the supply of S. filipendula as a substrate and feeding resource without the pressures in the natural environment could have influenced the preference for this alga by $C$. filosa, such that the nutritional quality of $S$. filipendula could have been a determining factor in the choice of algae. Jernakoff et al. (1996) showed that S. filipendula has good nutritional quality and palatability, which could favor the choice of this alga by herbivorous amphipods. The use as a preferential habitat and the consumption of brown algae has been reported for many ampithoid species (Hay et al., 1990; Duffy and Hay, 1991; Cruz-Rivera and Hay, 2001). 
Sunampithoe pelagica showed a different pattern from the other ampithoids, with low density on $G$. stupocaulon. This may be associated with the presence of $C$. filosa and $A$. ramondi, which are more aggressive and larger (Brawley and Adey, 1981) and might competitively exclude $S$. pelagica.

For Hyale nigra, the lack of feeding preferences and habitat selection in both the field and the laboratory may be related to the omnivorous habit of the species. Other studies recorded the highly mobility and wide distribution of $H$. nigra on different substrates, and also the use of a variety of food items (Tararam et al., 1985; Ruffo, 1998).

We conclude that in natural conditions, the choice of habitat and the feeding preference of ampithoids, especially C. filosa, are mainly influenced by local environmental characteristics. It is probable that the search for food and the selection of habitat are determined by structural characterisitics of the algae, which offer shelter and protection from predators. For $H$. nigra, apparently environmental pressures were not the principal factors that influenced its feeding preference and habitat selection, which were possibly more related to its high mobility and varied diet.

ACKNOWLEDGMENTS - The authors thank Pedro H.C. Pereira and Jairo Zancaner Junior for their help with the experiments and sampling, and anonymous reviewers for suggestions and comments.

\section{REFERENCES}

Arrontes, J. 1990. Diet, food preference and digestive efficiency in intertidal isopods inhabiting macroalgae. Journal of Experimental Marine Biology and Ecology, 139: 231-249.

Arrontes, J. 1999. On the evolution of interactions between marine mesoherbivores and algae. Botanica Marina, 42: 137-155.

Brawley, S.H. 1992. Mesoherbivores. p. 235-263. In: John, D.M.; Hawkins, S.J. and Price J.H. (eds), Plantanimal Interactions in the Marine Benthos. Systematics Associations Special, Vol. 46. New York, Oxford University Press.

Brawley, S.H. and Adey, W.H. 1981. The effects of micrograzers on algal community structure in a coral reef microcosm. Marine Biology, 61: 167-178.

Conlan, K.E. 1982. Revision of the gammaridean amphipod family Ampithoidae using numerical analytical methods. Canadian Journal of Zoology, 60: 2015-2027.

Cruz-Rivera, E. and Hay, M.E. 2001. The effects of diet mixing on consumer fitness: macroalgae, epiphytes, and animal matter as food for marine amphipods. Oecologia, 123: 252-264.

Duffy, J.E. and Hay, M.E. 1991. Food and shelter as determinants of food choice by an herbivorous marine amphipod. Ecology, 72: 1286-1298.

Duffy, J.E. and Hay, M.E. 2000. Strong impacts of grazing amphipods on the organization of a benthic community. Ecological Monographs, 70: 237-26.

Duffy, J.E.; Macdonald, K.S.; Rhode, J.M. and Parker, J.D. 2001. Grazer diversity, functional redundancy and productivity in seagrass beds: an experimental test. Ecology, 82: 2417-2434.

Hay, M.E. 1992. The role of seaweed chemical defenses in the evolution of feeding specialization and in the mediation of complex interactions. p. 93-118. In: V.J. Paul (ed), Ecological Roles of Marine Natural Products. New York, Academic Press.

Hay, M.E.; Duffy, J.E. and Fenical, W. 1990. Host-plant specialization decreases predation on a marine amphipod: an herbivore in plant's clothing. Ecology, 71: 733-743.

Hay, M.E.; Duffy, J.; Pfister C.A. and Fenical, W. 1987. Chemical defense against different marine herbivores: are amphipods insect equivalents? Ecology, 68: 1567-1580.

Hay, M.E.; Pawlik, J.R.; Duffy, J.E. and Fenical, W. 1989. Seaweed-herbivore-predator interactions: host-plant specialization reduces predation on small herbivores. Oecologia, 81: 418-427.

Hughes, R.N. 1980. Optimal foraging theory in the marine context. Oceanography and Marine Biology: An Annual Review, 18: 423-481.

Iribarne, O. 1996. Habitat structure, population abundance and the opportunity for selection on body weight in the amphipod Eogammarus oclairi. Marine Biology, 127: 143150.

Isaksson, I.; Pihl, L. and Montfrans, J. 1994. Eutrophicationrelated changes in macrovegetation and foraging of young cod (Gadus morhua L.): a mesocosm experiment. Journal of Experimental Marine Biology and Ecology, 177: 203-217.

Jacobucci, G.B. and Leite, F.P.P. 2002. Distribuição vertical e flutuação sazonal da macrofauna vágil associada a Sargassum cymosum C. Agardh, na praia do Lázaro, Ubatuba, São Paulo, Brasil. Revista Brasileira de Zoologia, 19(1): 87-100.

Jacobucci, G.B.; Tanaka, M.O. and Leite, F.P.P. 2009. Temporal variation of amphipod assemblages associated with Sargassum filipendula (Phaeophyta) and its epiphytes in a subtropical shore. Aquatic Ecology, 43: 1031-1040.

Jernakoff, P.; Brearley, A. and Nielsen, J. 1996. Factors affecting grazer-epiphyte interactions in temperate seagrass meadows. Oceagraphy and Marine Biology: An Annual Review, 34: 109-162.

Jormalainen, V.; Honkanen, T. and Heikkila, N. 2001. Feeding preferences and performance of a marine isopod on seaweeds hosts: cost of habitat specialization. Marine Ecology Progress Series, 220:219-230.

Klumpp, D.W.; Salita-Espinosa, J.T. and Fortes, M.D. 1992. 
The role of epiphytic periphiton and macroinvertebrate grazer in the trophic flux of a tropical seagrass community. Aquatic Botany, 43: 327-349.

Leite, F.P.P.; Güth, A.Z. and Jacobucci, G.B. 2000. Temporal comparison of gammaridean amphipods of Sargassum cymosum on two rocky shores in southeastern Brazil. Nauplius, 8(2): 227-236.

Lubchenco, J. and Gaines, S.D. 1981. A unified approach to marine plant-herbivore interactions. I. Populations and communities. Annual Review of Ecology and Systematics, 12: 405-437.

Masunari, S. and L. Forneris. 1981. O ecossistema fital - uma revisão. p. 149-172. In: Seminários de Biologia Marinha. Academia Brasileira de Ciências, Rio de Janeiro.

Mattila, J. 1992. The effect of habitat complexity on predation efficiency of perch (Perca fluviatilis L.) and ruffe (Gymnocephalus cernutus) (L.). Journal of Experimental Marine Biology and Ecology, 157: 55-67.

Mattingly, H.T. and Butler, M.J. 1994. Laboratory predation on the Trinidadian guppy: implications for the sizeselective predation hypothesis and guppy life history evolution. Oikos, 69: 54-64.

Nelson, W.G. 1979. An analysis of structural pattern in an eelgrass (Zostera marina L.) amphipod community. Journal of Experimental Marine Biology and Ecology, 39: 231- 264.

Nicotri, M.E. 1980. Factors involved in herbivore food preference. Journal of Experimental Marine Biology and Ecology, 42: 13-26.

Norton, T.A. and Benson, M.R. 1983. Ecological interactions between the brown seaweed Sargassum muticum and its associated fauna. Marine Biology, 75: 169-177.

Pereira, P.H.C. and Jacobucci, G.B. 2008. Diet and feeding behavior of Malacoctenus delalandii (Perciformes: Labrisomidae). Biota Neotropica, 8(3): 141-149.

Perreira, R.C. and Yoneshigue-Valentin, Y. 1999. The role of polyphenols from the tropical brown alga Sargassum furcutum on the feeding by amphipod herbivores. Botanica Marina, 42: 441-448.

Ruffo, S. 1998. The Amphipoda of the Mediterranean. Mémoires de l'Institut Océanographique, 13:1-959.

Serejo, C.S. 2004. Cladistic revision of talitroidean amphipods (Crustacea, Gammaridea), with a proposal of a new classification. Zoologica Scripta, 33: 551-586.

Stoner, A.W. 1980. Perception and choice of substratum by epifaunal amphipods associated with seagrasses. Marine Ecology Progress Series, 3: 105-111.

Széchy, M.T.M. and Paula, E.J. 2000. Padróes estruturais quantitativos em bancos de Sargassum (Phaeophyta, Fucales) do litoral dos estados do Rio de Janeiro e São Paulo, Brasil. Revista Brasileira de Botânica, 23(2): 121132.

Szlávecz, K. 1985. The effect of microhabitats on the leaf litter decomposition and on the distribution of soil animals. Holarctic Ecology, 8: 33-38.

Tararam, A.S.; Wakabara, Y. and Mesquita, H.S.L. 1985. Feeding habits of Hyale media (Dana, 1853) (CrustaceaAmphipoda). Boletim do Instituto Oceanográfico, 33: 193199.

Taylor, R.B. and Cole, R.G. 1994. Mobile epifauna on subtidal brown seaweeds in northeastern New Zealand. Marine Ecology Progress Series, 115: 271-282.

Thomas, J.D. 1993. Biological monitoring and tropical biodiversity in marine environments: a critique with recommendations, and comments on the use of amphipods as bioindicators. Jornal of Natural History, 27: 795-806.

Van Montfrans, J.; Orth, R.J. and Vay, S.A. 1982. Preliminary studies of grazing by Bittium varium on eelgrass periphyton. Aquatic Botany, 14: 75-89.

Wakabara, Y.; Flynn, M. and Tararam, A.S. 1996. Ingestion and selection of suprabenthic crustaceans by small-sized fishes in a lower saltmarsh system. Revista Brasileira de Oceanografia, 44: 89-103. 